Neurosurg Focus 17 (3):E3, 2004 Click here to return to Table of Contents

\title{
Cervical arthroplasty: material properties
}

\author{
Harvey E. Smith, M.D., David W. Wimberley, M.D., And Alexander R. Vaccaro, M.D. \\ Department of Orthopaedic Surgery and the Rothman Institute, Thomas Jefferson University, \\ Philadelphia, Pennsylvania
}

\begin{abstract}
Discectomy, decompression, and fusion are traditionally used to manage cervical disc disease accompanied by neural element compression that is refractory to conservative management. Concerns regarding stress at levels adjacent to fusion and possible adjacent-level degeneration as well as a desire to maintain a more normal biomechanical environment have led to investigation of cervical disc replacement as an alternative to fusion procedures. Cervical disc prostheses currently under investigation are constructed of predominantly metal-on-polyethylene or metal-on-metal bearing surfaces, and use roughened titanium surfaces and osteoconductive coatings to facilitate fixation. The unique anatomy and biomechanics of the cervical spine must be considered when extrapolating from the experience of appendicular arthroplasty and lumbar disc replacement.
\end{abstract}

\section{KEY WoRDS • cervical decompression • discectomy • cervical disc prosthesis • biomaterial}

Discectomy, decompression, and interbody fusion, with or without anterior instrumentation of the cervical spine, are the traditional anterior surgical strategies used to manage disc disease accompanied by neural element compression that is refractory to conservative management. In an appropriately selected patient, anterior discectomy and fusion provide reproducible and satisfactory clinical outcomes in the resolution of radicular symptoms as well as the cessation of myelopathy progression. There is concern, however, that fusion may increase stress at adjacent levels. ${ }^{11,25}$ Clinical studies have demonstrated a predictable rate of adjacent-level degeneration. Whether this represents the natural progression of the primary disease process culminating in the index surgical procedure ${ }^{16}$ or is the result of the increased stress placed on the adjacent open segments due to the stiffness of the fusion mass is controversial. The goal of cervical disc replacement is to provide the symptomatic relief of neural decompression through a cervical decompression without the resulting loss of motion associated with a fusion procedure.

Proponents of cervical intervertebral disc replacement laud the ability to perform a decompressive procedure while maintaining motion at the affected level. Few would argue against the desire for maintenance of some degree of pain-free motion in a more physiological biomechanical environment at an interspace previously relegated to fusion or loss of segmental motion. It is reasonable to presume that maintenance of motion at a decompressed interspace may result in improved load transfer and reduced stress on the adjacent intervertebral discs and posterior elements, although this has yet to be demonstrated conclusively in the cervical spine.

Abbreviations used in this paper: $\mathrm{PCM}=$ porous coated motion; $\mathrm{ROM}=$ range of motion; $\mathrm{TiCaP}=$ titanium tricalcium phosphate; $\mathrm{VB}=$ vertebral body.
In the lumbar spine, Cunningham, et al., ${ }^{9}$ assessed adjacent-level ROM in cadaveric spines, comparing intact specimens against an unconstrained artificial disc (Charité), a cylindrical anterior fusion cage (known as the BAK cage), and BAK cage with posterior pediclescrew/rod fixation. There was no significant difference between the intact and Charité treatments with respect to adjacentlevel ROM in axial rotation, flexion/extension, or lateral bending. Nevertheless, according to these authors there was a marked increase in adjacent-level ROM in the BAK and BAK with pedicle screws treatments. Additionally, evaluations of cervical disc prostheses in cadaveric specimens have shown that these devices are able to restore primary stability and to replicate normal motion characteristics, with and without removal of the posterior longitudinal ligament. ${ }^{26}$

Disc replacement has been shown to be a potentially viable alternative to fusion in the lumbar spine, with encouraging early clinical results. The third-generation Charité intervertebral artificial disc (Depuy Spine, Raynham, MA) has the longest-term follow up of the lumbar arthroplasty systems. The Charite intervertebral artificial disc is an unconstrained device consisting of two cobaltchromium-molybdenum endplates and a sliding polyethylene core. The prosthetic endplates contain teeth to dig into the vertebral endplates, which provides both shortand long-term stabilization. In a series of 50 patients evaluated at 2-year follow-up visits, Zeegers, et al., ${ }^{32}$ reported a $70 \%$ satisfactory clinical outcome. Cinotti, et al., ${ }^{4}$ found similar results in their clinical cohort of 46 patients at the 2-year follow-up review. Lemaire, et al., 22 reported good or excellent clinical results in $85 \%$ of 105 patients treated with the Charité prosthesis at a minimum 5-year followup duration.

In contrast to the unconstrained polyethylene core of the Charité prosthesis, the ProDisc (Synthes, Paoli, PA) 
H. E. Smith, D. W. Wimberley, and A. R. Vaccaro

lumbar prosthesis consists of two cobalt-chromium-molybdenum endplates with a polyethylene insert that is fixed to the inferior endplate. Preliminary data from 53 patients who were randomized to groups receiving fusion or disc replacement demonstrated significantly reduced pain and disability in the disc replacement group at early (6-week and 3-month) follow-up review compared with those in the fusion group, and significantly greater motion at the instrumented level at the 6-month follow-up review. ${ }^{10}$ The FlexiCore (SpineCore, Inc., Summit, NJ) and Maverick (Medtronic Sofamor Danek, Memphis, TN) lumbar disc prostheses differ from the Charité and ProDisc by having metal-on-metal bearing surfaces (cobalt-chromium alloy). In summary, all contemporary lumbar disc replacement prostheses currently being tested in US clinical trials are composed of cobalt-chromium alloys with metal-on-metal or metal-on-polyethylene bearing surfaces.

Biomaterial considerations in cervical disc arthroplasty have certain similarities to those of lumbar disc and total joint arthroplasty. The articulating bearing surfaces must be designed to tolerate anticipated loading without fatigue or fracture, minimize friction, and have superior wear characteristics and minimal debris generation. Nevertheless, the loads, and therefore the stresses seen in the materials of the cervical disc prostheses are substantially less than those of the lumbar spine. Bone ingrowth, which biologically affixes the implant to the VB, is specifically accommodated in certain designs to achieve a stable construct that will withstand the repetitive load cycles of the spine.

Although the successes and failures of appendicular arthroplasty provide a foundation of knowledge for the development of a successful cervical disc replacement, the unique biomechanical and anatomical environment of the spine raises several considerations. In contrast to the hip and knee, there is less bone stock in the cervical VB, and one will have considerably less latitude in tailoring bone cuts to fit a prosthesis. Furthermore, limited bone stock as well as the proximity of the spinal canal, neural elements, and vascular structures will likely make revision disc arthroplasty a technically daunting procedure. As in the lumbar spine, it will be important to achieve as much coverage of the bone endplates as possible with the cervical prosthetic endplate. This will minimize the chance of subsidence of the prosthesis into the VB's central cancellous bone.

The mechanical properties of various metals and alloys have been extensively studied in the development of a variety of joint replacements. As in total joint arthroplasty, material considerations important in arthroplasty of the spine include resistance to corrosion in vivo, toughness, stiffness, brittleness, ductility, and ease of machinability. Stress shielding around the implant may be more substantial with materials that differ significantly from bone in their mechanical properties. Compatibility with computerized tomography and magnetic resonance imaging is of particular concern in cervical disc arthroplasty for longterm evaluation of the implant and surrounding structures as it relates to wear characteristics and junctional degeneration.

\section{Metal Alloys}

Three metals are used in contemporary disc arthroplasty: Ti and Ti-based alloys, stainless steel alloys, and cobalt alloys (Table 1). ${ }^{15}$

Stainless Steel Alloys. Stainless steel alloys contain iron, carbon, chromium, nickel, and molybdenum. They are inexpensive and have a long history of clinical use in spine implants. Chromium oxide formation on the surface of the metal resists corrosion. In general, the mechanical properties of the stainless steel alloys are inferior to titanium and chromium-based ones, although they have significantly greater ductility. Additionally, stainless steel alloys have inferior biocompatibility compared with titanium, and the significant imaging artifacts caused by stainless steel alloys make long-term imaging of spinal implants problematic.

Titanium Alloys. Titanium is used both as commercially pure titanium and as an alloy composed of varying amounts of titanium, aluminum, and vanadium. Titanium oxidizes to form $\mathrm{TiO}_{2}$, and this surface oxide film provides excellent resistance to corrosion, providing titanium and its alloys with good biocompatibility. Titaniumaluminum-vanadium alloys have mechanical properties superior to commercially pure titanium, and are more commonly used in total joint replacement components. Commercially pure titanium is frequently used in porous coatings to promote the ingrowth of bone.

Cobalt-Chromium Alloys. Cobalt-chromium alloys consist of cobalt, chromium, and molybdenum. The molybdenum decreases the grain size of the alloy, yielding improved mechanical properties. Nickel can be added to the alloy to improve resistance to corrosion, although concerns remain regarding the possibility of hypersensitivity reactions. Chromium oxide forms on the surface of cobalt-chromium-molybdenum, providing resistance to corrosion.

\section{Implant Incorporation}

Cervical disc replacement prostheses should be expected to withstand the repetitive stress and strain of weight bearing and motion that occurs in the cervical spine over a life span of approximately 30 to 40 years. Secure implant fixation is paramount to implant longevity. The generation of particulate wear debris may result in osteolysis, possibly leading to implant loosening and subsequent segmental instability. Furthermore, implant migration may

TABLE 1

Properties of materials used in prosthetic cervical discs*

\begin{tabular}{lcccccc}
\hline \hline Material & $\begin{array}{c}\text { Young } \\
\text { Modulus } \\
(\mathrm{GPa})\end{array}$ & $\begin{array}{c}\text { Elastic } \\
\text { Limit } \\
(\mathrm{MPa})\end{array}$ & $\begin{array}{c}\text { Ultimate } \\
\text { Strength } \\
(\mathrm{MPa})\end{array}$ & $\begin{array}{c}\text { Fatigue } \\
\text { Strength } \\
(\mathrm{MPa})\end{array}$ & $\begin{array}{c}\mathrm{HVN} \\
(\mathrm{kg} / \mathrm{mm}) *\end{array}$ & $\begin{array}{c}\text { Elongation } \\
\text { at Fracture } \\
(\%)\end{array}$ \\
\hline stainless steel & 190 & 792 & 930 & $241-820$ & $130-180$ & $43-45$ \\
CoCrMo & $210-253$ & $448-841$ & $655-1277$ & $207-950$ & $300-400$ & $4-14$ \\
TiCaP & 110 & 485 & 760 & 300 & $120-200$ & $14-18$ \\
Ti-6Al-4V & 116 & $897-1034$ & $965-1103$ & $620-689$ & 310 & 8 \\
\hline
\end{tabular}

$*$ HVN $=$ Hardness Vickers Number. 
have catastrophic effects due to the proximity of the spinal canal and adjacent visceral and vascular structures. In total joint arthroplasty, implant fixation has centered on the use of methylmethacrylate cement or the use of implant surfaces designed to promote bone ingrowth. Due to the proximity of the spinal canal, decreased bone volume, and the technical considerations associated with the anterior approach for disc replacement insertion, the use of cement for implant fixation is not currently considered to be a viable option. Roughened surface finishes composed of titanium have resulted in improved initial implant fixation and are believed to support improved bone ingrowth onto the surface of joint arthroplasty at the host-prosthesis interface.

Osteoconductive coatings of hydroxyapatite and tricalcium phosphate are believed to result in improved ingrowth into femoral and tibial components. Radiostereometric analysis of porous hydroxyapatite tibial components at 2 years postimplantation demonstrates fixation comparable to that of cemented implants. ${ }^{28}$ As a result, TiCaP is currently used in the Charite lumbar and PCM (Cervitech, Rockaway, NJ) cervical artificial discs. The $\mathrm{TiCaP}$ is a three-layer coating in which two layers of commercially pure titanium are plasma-sprayed onto the back of the cobalt-chromium endplates. The first layer of titanium is a bond coating with pore sizes of 75 to $300 \mu \mathrm{m}$. The CaP portion of TiCaP's coating consists of hydroxyapatite as a nucleator as well as a physiological adhesive (calcium phosphate hydroxyapatite) with a calcium/phosphate ratio of 1:0. This calcium layer is electrochemically deposited to the underlying titanium coating and serves to optimize mineralized anchorage at the vertebral endplates (Fig. 1).

The electrochemical coating procedure retains the open cell structure of the underlying titanium for optimal bone

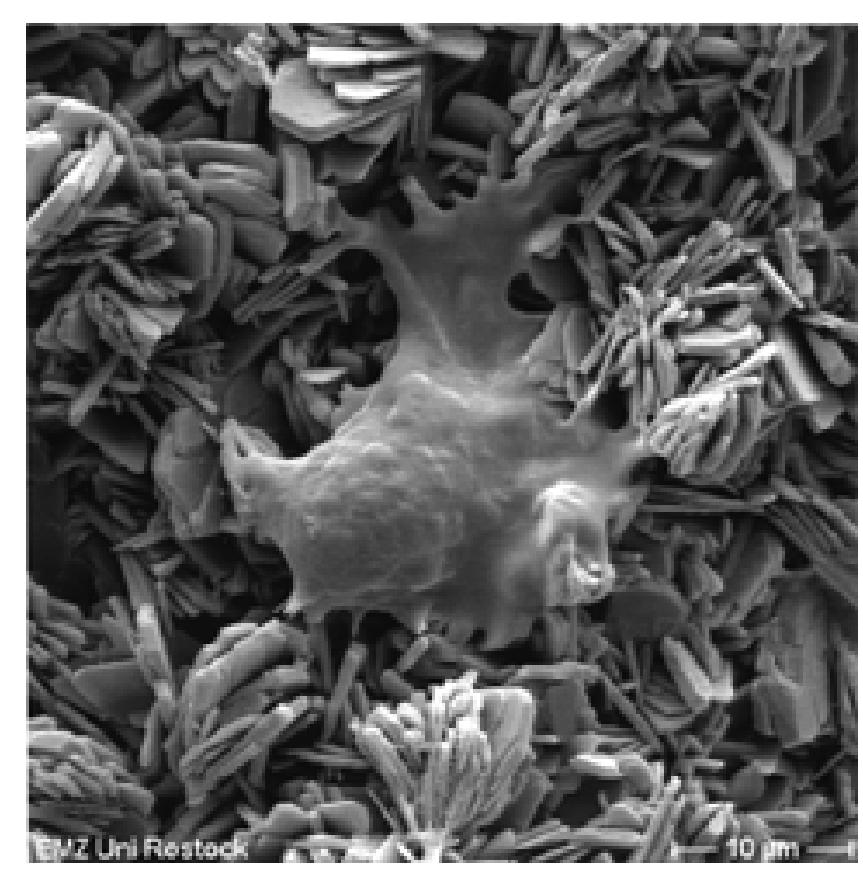

Fig. 1. Photomicrograph of an in vitro cell culture reflecting osteoblast cell line ingrowth on the tricalcium phosphate surface after 30 hours. Original magnification $\times 2700$. ingrowth. The structure of the tricalcium phosphate itself is finely crystalline, with crystallites fixed to the implant surface in the shape of platelets or pins in a nearly vertical alignment. The vertical dimension of this structure is approximately $20 \mu \mathrm{m}$ and features an extremely strong bond, which is not comparable to the traditionally plasma-sprayed hydroxyapatite. Concern has been raised that debonded (traditional) hydroxyapatite may lead to thirdbody debris and accelerated wear, or may cause an immune response possibly leading to osteolysis. Nevertheless, McAfee, et al., ${ }^{27}$ described excellent bone ingrowth (mean ingrowth of $47.9 \%$ ) in a baboon model, with no accumulation of particulate wear debris with the TiCaPcoated Charitè (ACCENT AIGU) endplates at 6-month follow-up review. At present, the ProDisc has a pure titanium plasma-sprayed coating on its endplates.

\section{Bearing Surface}

Considerations applicable to the design of arthroplasty bearing surfaces include coefficients of friction at the articulating surfaces and mechanical load transfer through the joint, in addition to wear characteristics and the potential for debris generation at the articulating surface(s). Total joint arthroplasty experience provides substantial clinical and basic science data on the wear characteristics of metal-on-polyethylene articulations. A common consideration is the possibility of the generation of polyethylene wear debris that may lead to osteolysis. Given the proximity of the implants to the spinal canal, it is conceivable that such osteolysis in the setting of a total disc replacement may allow the hardware to migrate into the vicinity of the spinal cord and nerve roots. Cross-linking with gamma irradiation has been shown to decrease both the rate of polyethylene wear and the generation of particulate wear debris significantly. ${ }^{12,29}$ Cross-linking, however, alters the biomechanical characteristics of polyethylene. ${ }^{7,20,23}$ Specifically, irradiation decreases the crystallinity, yield strength, modulus of elasticity, and proportion of strain to failure. Decreased crystallinity may lead to increased creep deformation. Experience with total knee arthroplasty indicates that the polyethylene spacer should have a minimum thickness of 6 to $8 \mathrm{~mm}$ due to the cold flow limit of $22 \mathrm{~N} / \mathrm{mm},{ }^{15}$ and this size has been suggested empirically as a minimum thickness for lumbar disc replacement. Given the decreased magnitude of loads transmitted through the cervical spine, a thinner polyethylene spacer may be adequate in cervical arthroplasty; however, further work needs to be done to define the optimal insert thickness in cervical disc replacement.

Metal-on-metal articulations have demonstrated reduced wear rates when compared with metal-on-polyethylene devices in appendicular arthroplasties. ${ }^{1,3}$ In addition, they have been reported to produce significantly less wear debris..$^{2,3}$ Although the debris generated from wear is markedly less volumetrically with a metal-on-metal articulation, the debris particles are greater in number, smaller in size, and predominantly composed of heavy metals. Patients with metal-on-metal hip replacements have been found to have increased serum and urine levels of chromium. ${ }^{24}$ No adverse clinical effects have been attributed to the deposition of heavy metal, but the biological significance remains uncertain at this time. ${ }^{18,19}$ 
Ceramics have recently become increasingly popular for total hip arthroplasty bearing surfaces. These articulations have demonstrated superior wear characteristics compared with metal-on-polyethylene and similar wear compared with metal-on-metal articulations. .,6,30 $^{5}$ There is clinical concern regarding the possibility of catastrophic implant failure because of fracture of the ceramic bearing surface. Therefore, ceramic components are very difficult to use in applications in which relatively thin components are necessary. To date there is only one cervical total disc arthroplasty design (Cervidisc) in which bearing surfaces of zirconia ceramic are used.

Contemporary bearing surfaces used in disc replacements are either metal-on-metal or metal-on-polyethylene materials. To date, there have been no reports of significant osteolysis in the European trials of the Charite or ProDisc lumbar disc prosthesis. The lower magnitude of loads, decreased total bearing surface area, and limited ROM of cervical disc replacements relative to other weight-bearing total joint replacements may limit the amount of wear debris generated in disc arthroplasty. The disc space lacks a synovium, which is a significant source of proinflammatory mononuclear cells, and this may further attenuate any immunological or inflammatory response to particulate wear debris. ${ }^{17,27}$

Concerns have been raised regarding the role of the bearing surface as a shock absorber. Current clinical data in which investigators have analyzed the role of the native disc space in shock absorption and force transmission is limited. Both metal-on-polyethylene and metal-on-metal bearing surfaces currently under investigation in lumbar disc replacement have been shown to have identical vibration and shock transmissibility, with a limited role as a shock absorber. ${ }^{21}$ The saline-filled polyurethane ring used in the Bryan disc replacement device allows the prosthesis to be compressed. This should allow it to provide some shock absorption in vivo; however, the clinical or biomechanical relevance of this feature has not yet been demonstrated or published in the literature.

\section{Currently Available Cervical Disc Prostheses}

The Prestige Artificial Cervical Disc. The Prestige Artificial Cervical Disc (Medtronic Sofamor Danek; Fig. 2) is a stainless steel, metal-on-metal semiconstrained bearing surface. It is an evolution of the joint developed by Cummins, et al., ${ }^{8}$ which was based on a ball-and-socket design. The Prestige uses an ellipsoid saucer on the lower component to articulate with the dome of the superior component. In 2-year follow-up evaluations of 15 patients, the prosthesis maintained intervertebral height as well as motion at the surgically treated level. ${ }^{31}$ Evidence of stress shielding of the anterior vertebral endplate junction was noted, but did not progress after 12 months.

The Bryan Cervical Disc Prosthesis. The Bryan Cervical Disc (Medtronic Sofamor Danek; Fig. 3) consists of two titanium alloy shells with a polyurethane nucleus. A titanium porous coating is applied to the bone-implant interface of each shell to facilitate ingrowth of bone. A polyurethane sheath surrounds the nucleus, creating an enclosed articulating environment. Sterile saline is injected into this sheath and functions as a lubricant. Preliminary data have been reported on a cohort of 60 patients. ${ }^{13}$ At 1 -

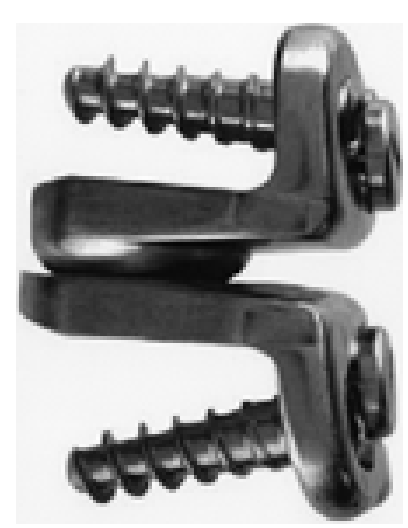

Fig. 2. Photograph of the Prestige disc manufactured by Medtronic Sofamor Danek.

year follow-up review in 30 of the 60 patients, there was no subsidence of the device and no evidence of spondylotic bridging. Anterior-to-posterior migration was a concern in two of the devices. The ROM demonstrated on flexion/extension radiographs was variable, ranging from 1 to $21^{\circ}$. Several cases of anterolateral paravertebral ossification occurring after Bryan disc implantation have been reported anecdotally and in the literature. ${ }^{14}$ This phenomenon may be a consequence of the bone preparation phase prior to implant insertion, although further research and observation are necessary to understand this observation more fully.

The ProDisc-C Implant. The ProDisc-C cervical disc replacement (Synthes; Fig. 4) is similar in design to the ProDisc lumbar disc replacement. It is composed of two cobalt-chromium-molybdenum endplates with a metalon-polyethylene bearing surface. The polyethylene insert is fixed to the inferior endplate. Bone ingrowth into the

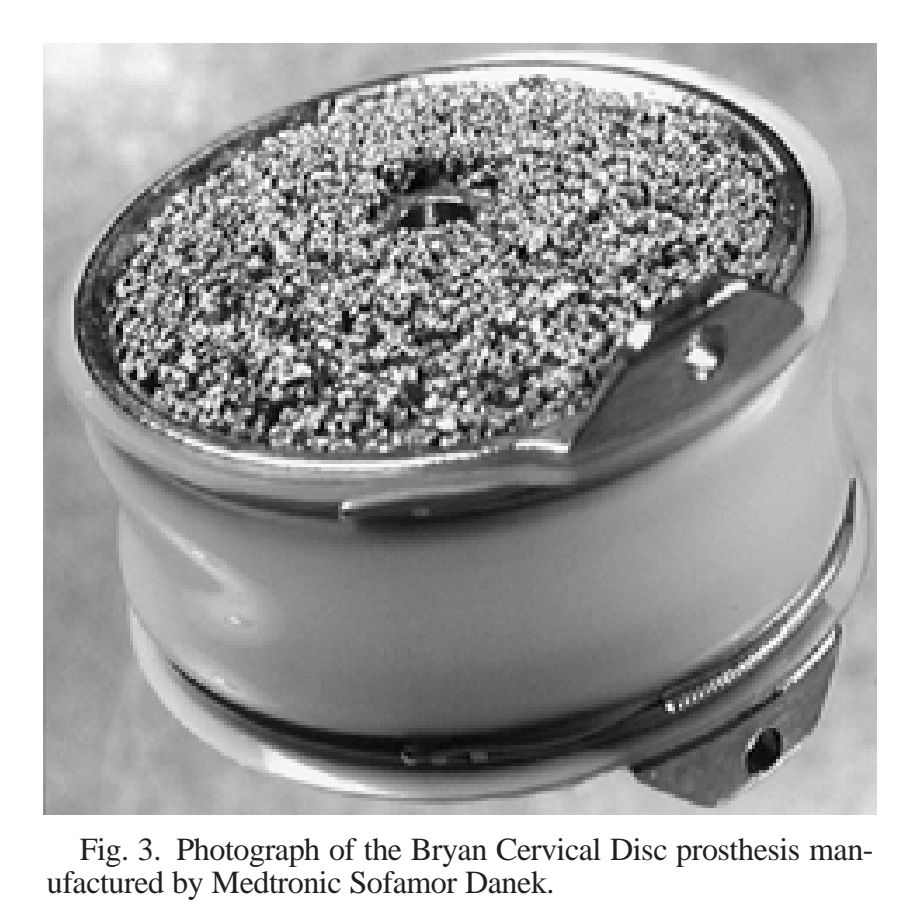




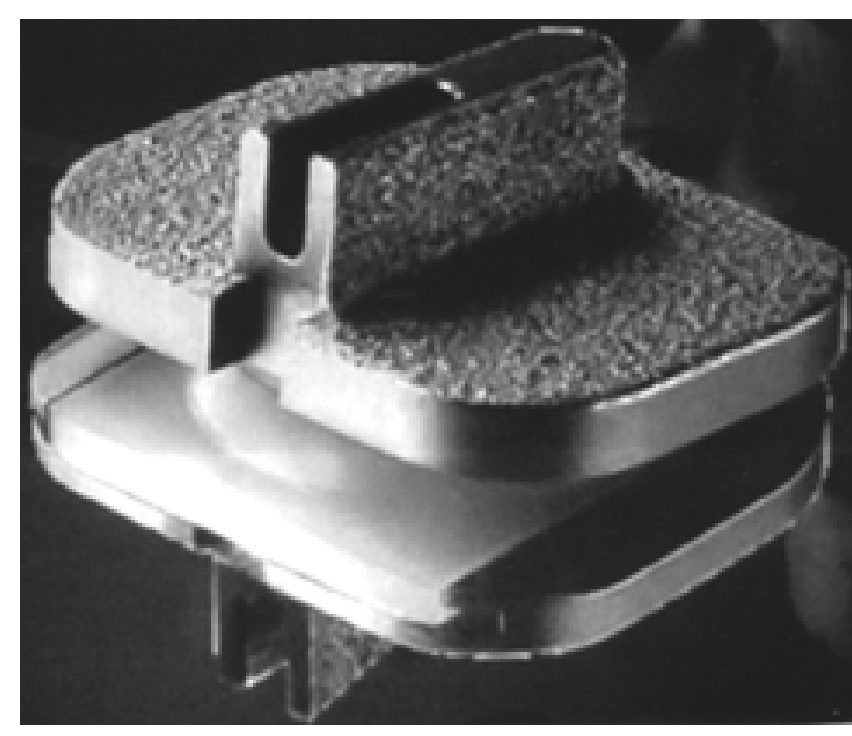

Fig. 4. Photograph of the ProDisc-C cervical disc replacement device manufactured by Synthes.

plasma-sprayed titanium surfaces at the bone-implant interface allows for long-term stability. A central keel that interdigitates with the VB is designed to provide immediate implant stability.

The CerviCore Device. The CerviCore disc replacement device (SpineCore, Inc.; Fig. 5) features opposing cobalt-chromium bearing surfaces that are nested to provide a center of rotation below the bottom baseplate for flexion and extension, and a center of rotation above the top baseplate for lateral bending. The configuration of the surfaces also enables the baseplates to distract away from one another after extended axial rotation. The VB contact surfaces of the baseplates feature a titanium plasma spray and three spikes. The implantation instrumentation includes an insertion plate that holds the baseplates as a single unit for placement between the vertebrae. After placement of the device, bone screws can be installed through holes in the baseplates' anterior flanges.

The PCM Prosthesis. The PCM cervical disc prosthesis (Cervitech; Fig. 6) features two porous-surfaced $\mathrm{Co}-\mathrm{Cr}$ endplates, with a polyethylene bearing surface attached to the caudal endplate. The lateral portions of the bone endplates are osteodense compared with the central endplates. This is a reflection of the osteosclerotic uncovertebral clefts and articulation in this region. Consequently, the PCM endplates were shaped to maximize support in the lateral areas. The surfaces of the endplates are coated with TiCaP. The typical press-fit fixation of the standard PCM may be augmented with vertebral screw fixation in special cases. The articulating surface of this prosthesis extends across the entire bearing surface, thus creating a larger radius of articulation and increased translation through the rotational arc (Fig. 7). This also results in unconstrained translational motion, making the PCM a surface replacement device with kinematics controlled by the surrounding soft-tissue structures.

Early clinical results indicate that in appropriately selected patients (single-level disc disease with radicular

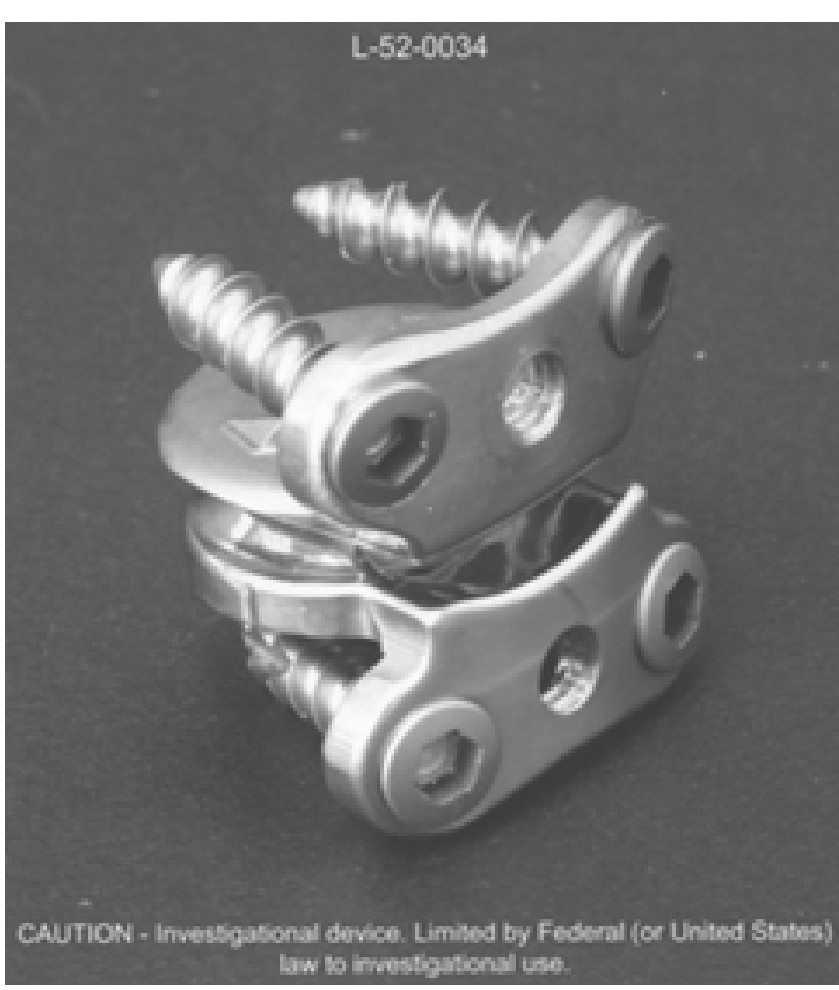

Fig. 5. Photograph of the CerviCore disc replacement device manufactured by SpineCore, Inc.

symptoms) cervical disc replacement may yield results similar to discectomy and fusion while maintaining more normal joint kinematics. ${ }^{13}$ There appears to be a growing consensus that the endplates should be composed of either $\mathrm{Co}-\mathrm{Cr}$ alloys, stainless steel, titanium, or titanium alloys. The role of osteoconductive coatings on the bone-implant interface is still under investigation; however, preliminary results in nonhuman primate models indicate that hydroxyapatite coatings may encourage bone ingrowth into disc

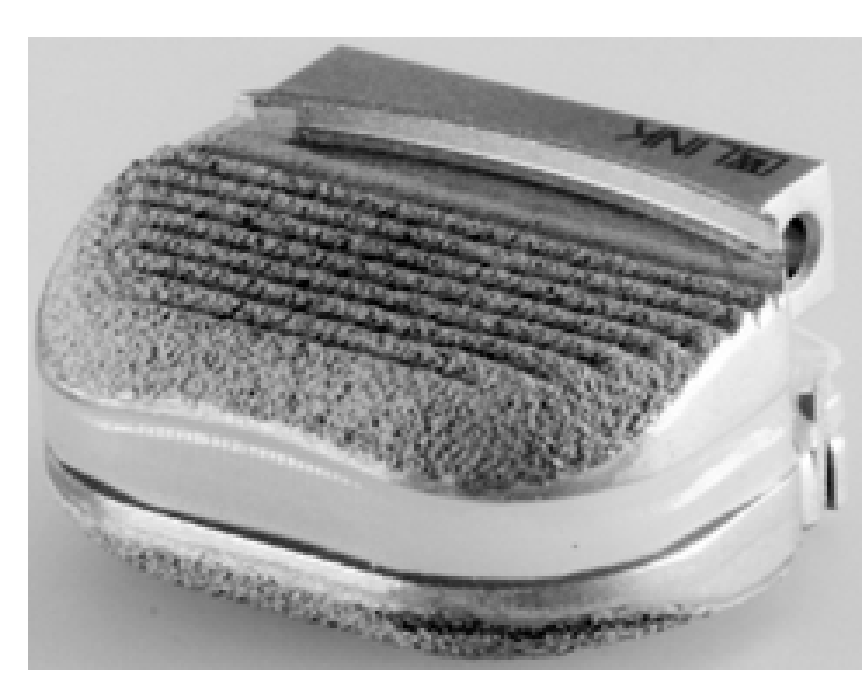

Fig. 6. Photograph of the PCM artificial cervical disc manufactured by Cervitech. 


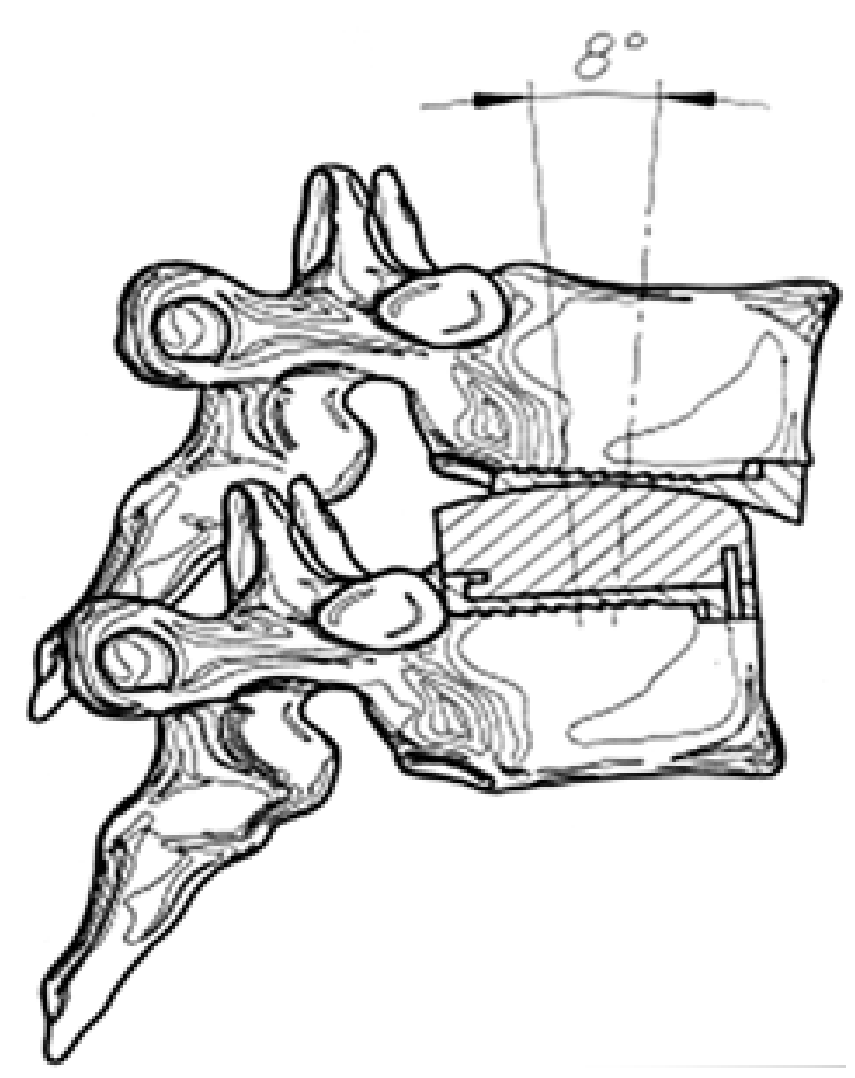

Fig. 7. Drawing showing the motion pattern of the PCM prosthesis.

prostheses that is at least comparable to that observed in joint replacement. ${ }^{27}$

All clinical data from arthroplasty studies in the US are preliminary, with follow-up intervals of 2 years or less. Further longitudinal follow up is necessary to assess the long-term clinical results of disc replacement and how this compares with decompression and fusion as far as longterm symptom relief, disease progression at the surgical and adjacent levels, and the need for repeated surgery.

\section{References}

1. Anissian HL, Stark A, Good V, et al: The wear pattern in metalon-metal hip prostheses. J Biomed Mater Res 58:673-678, 2001

2. Anissian HL, Stark A, Gustafson A, et al: Metal-on-metal bearing in hip prosthesis generates 100-fold less wear debris than metal-on-polyethylene. Acta Orthop Scand 70:578-582, 1999

3. Campbell P, Shen FW, McKellop H: Biologic and tribologic considerations of alternative bearing surfaces. Clin Orthop 418:98-111, 2004

4. Cinotti G, David T, Postacchini F: Results of disc prosthesis after a minimum follow-up period of 2 years. Spine 21: 995-1000, 1996

5. Clarke IC, Good V, Williams P, et al: Ultra-low wear rates for rigid-on-rigid bearings in total hip replacements. Proc Inst Mech Eng 214:331-347, 2000

6. Clarke IC, Gustafson A: Clinical and hip simulator comparisons of ceramic-on-polyethylene and metal-on-polyethylene wear. Clin Orthop 379:34-40, 2000

7. Collier JP, Currier BH, Kennedy FE, et al: Comparison of cross-linked polyethylene materials for orthopaedic applications. Clin Orthop 414:289-304, 2003

8. Cummins BH, Robertson JT, Gill SS: Surgical experience with an implanted artificial cervical joint. J Neurosurg 88:943-948, 1998

9. Cunningham BW, Gordon JD, Dmitriev AE, et al: Biomechanical evaluation of total disc replacement arthroplasty: an in vitro human cadaveric model. Spine 28:S110-S117, 2003

10. Delamarter RB, Fribourg DM, Kanim LE, et al: ProDisc artificial total lumbar disc replacement: introduction and early results from the United States clinical trial. Spine 28:S167-S175, 2003

11. DiAngelo DJ, Roberston JT, Metcalf NH, et al: Biomechanical testing of an artificial cervical joint and an anterior cervical plate. J Spinal Disord Tech 16:314-323, 2003

12. D'Lima DD, Hermida JC, Chen PC, et al: Polyethylene crosslinking by two different methods reduces acetabular liner wear in a hip joint wear simulator. J Orthop Res 21:761-766, 2003

13. Goffin J, Casey A, Kehr P, et al: Preliminary clinical experience with the Bryan Cervical Disc Prosthesis. Neurosurgery 51: 840-847, 2002

14. Goffin J, Van Calenbergh F, van Loon J, et al: Intermediate follow-up after treatment of degenerative disc disease with the Bryan Cervical Disc Prosthesis: single-level and bi-level. Spine 28:2673-2678, 2003

15. Hallab N, Link HD, McAfee PC: Biomaterial optimization in total disc arthroplasty. Spine 28 (Suppl 20):S139-S152, 2003

16. Hilibrand AS, Carlson GD, Palumbo MA, et al: Radiculopathy and myelopathy at segments adjacent to the site of a previous anterior cervical arthrodesis. J Bone Joint Surg Am 81: 519-528, 1999

17. Howie DW, Vernon-Roberts B: The synovial response to intraarticular cobalt-chrome wear particles. Clin Orthop 232: 244-254, 1988

18. Jacobs JJ, Skipor AK, Patterson LM, et al: Metal release in patients who have had a primary total hip arthroplasty. A prospective, controlled, longitudinal study. J Bone Joint Surg Am 80: 1447-1458, 1998

19. Kornhauser C, Wróbel K, Wróbel K, et al: Possible adverse effect of chromium in occupational exposure of tannery workers. Ind Health 40:207-213, 2002

20. Kurtz SM, Villarraga ML, Herr MP, et al: Thermomechanical behavior of virgin and highly crosslinked ultra-high molecular weight polyethylene used in total joint replacements. Biomaterials 23:3681-3697, 2002

21. LeHuec JC, Kiaer T, Friesem T, et al: Shock absorption in lumbar disc prosthesis: a preliminary mechanical study. J Spinal Disord Tech 16:346-351, 2003

22. Lemaire JP, Skalli W, Lavaste F, et al: Intervertebral disc prosthesis. Results and prospects for the year 2000. Clin Orthop 337:64-76, 1997

23. Lewis G, Carroll M: Effect of crosslinking UHMWPE on its tensile and compressive creep performance. Biomed Mater Eng 11:167-183, 2001

24. Maezawa K, Nozawa M, Hirose T, et al: Cobalt and chromium concentrations in patients with metal-on-metal and other cementless total hip arthroplasty. Arch Orthop Trauma Surg 122:283-287, 2002

25. Matsunaga S, Kabayama S, Yamamoto T, et al: Strain on intervertebral discs after anterior cervical decompression and fusion. Spine 24:670-675, 1999

26. McAfee PC, Cunningham B, Dmitriev A, et al: Cervical disc replacement-porous coated motion prosthesis: a comparative biomechanical analysis showing the key role of the posterior longitudinal ligament. Spine 28 (Suppl 20):S176-S185, 2003

27. McAfee PC, Cunningham BW, Orbegoso CM, et al: Analysis of porous ingrowth in intervertebral disc prostheses: a nonhuman primate model. Spine 28:332-340, 2003

28. Onsten I, Nordqvist A, Carlsson AS, et al: Hydroxyapatite aug- 
mentation of the porous coating improves fixation of tibial components. A randomised RSA study in 116 patients. J Bone Joint Surg Br 80:417-425, 1998

29. Oonishi H, Clarke IC, Yamamoto K, et al: Assessment of wear in extensively irradiated UHMWPE cups in simulator studies. J Biomed Mater Res 68A:52-60, 2004

30. Rieker C, Konrad R, Schon R: In vitro comparison of the two hard-hard articulations for total hip replacements. Proc Inst Mech Eng 215:153-160, 2001

31. Wigfield CC, Gill SS, Nelson RJ, et al: The new Frenchay artificial cervical joint: results from a two-year pilot study. Spine 27:2446-2452, 2002
32. Zeegers WS, Bohnen LM, Laaper M, et al: Artificial disc replacement with the modular type SB Charite III: 2-year results in 50 prospectively studied patients. Eur Spine J 8: 210-217, 1999

Manuscript received April 29, 2004.

Accepted in final form July 26, 2004.

Address reprint requests to: Alexander R. Vaccaro, M.D., Department of Orthopaedic Surgery, Thomas Jefferson University and the Rothman Institute, Philadelphia, Pennsylvania 19107. email: alexvaccaro3@aol.com. 